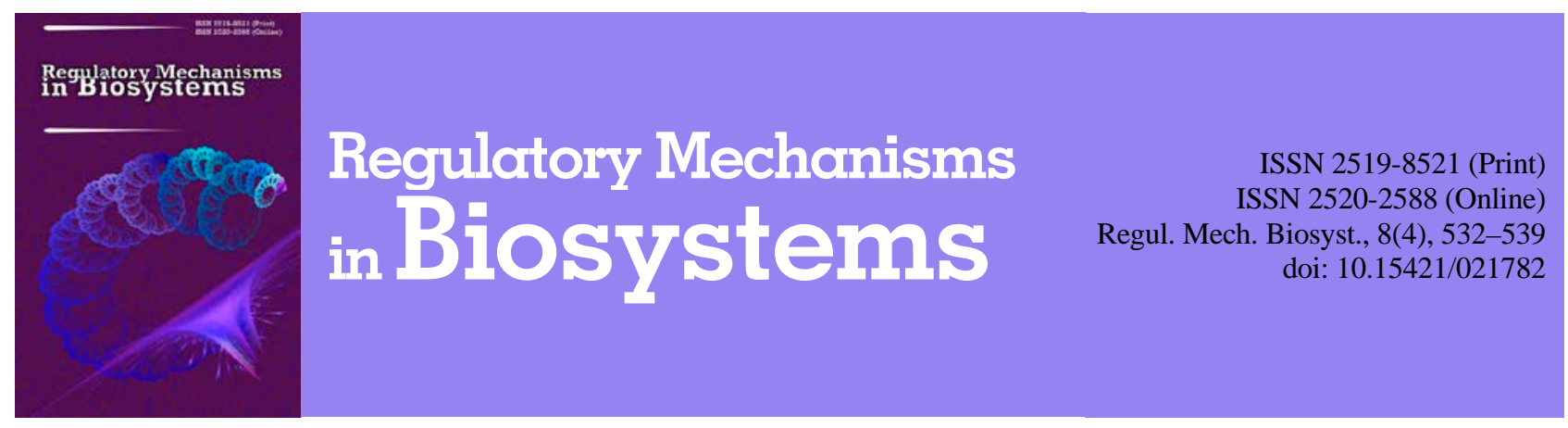

\title{
New finding of green algae with potential for algal biotechnology, Chlorococcum oleofaciens and its molecular investigation
}

\author{
Y. I. Maltsev, T. V. Konovalenko \\ Bogdan Khmelnitskiy Melitopol State Pedagogical University, Melitopol, Ukraine
}

Article info

Received 14.09.2017

Received in revised form 28.10.2017

Accepted 03.11.2017

Bogdan Khmelnitskiy Melitopol State Pedagogical University, Getmanska st., 20, Melitopol,

Zaporizhia region, 72312,

Ukraine.

Tel.: +38-096-548-34-36

E-mail:mz_5@ukr.net

\begin{abstract}
Maltsev, Y. I., \& Konovalenko, T. V. (2017). New finding of green algae with potential for algal biotechnology, Chlorococcum oleofaciens and its molecular investigation. Regulatory Mechanisms in Biosystems, 8(4), 532-539. doi:10.15421/021782

The practice of soil algology shows that algae from the order Chlamydomonadales are among the most poorly studied and difficult to identify due to the high heterogeneity of their morphology and ultrastructure. Only the involvement of molecular genetic methods usually makes it possible to determine their taxonomic status with high accuracy. At the same time, in the algae flora of Ukraine there are more than 250 species from the order Chlamydomonadales, the status of which in most cases is established exclusively on the basis of light microscopy. This work is devoted to the study of the biotechnologically promising green alga Chlorococcum oleofaciens, taking into account the modern understanding of its taxonomic status. Two new strains of this species, separated from samples of forest litter and oak forest soil (the Samara Forest, Dnipropetrovsk region), are described. The strains were studied at the morphological level by using light microscopy methods, as well as using molecular genetic methods based on the studies of the nucleotide genes sequences of the 18S ribosomal DNA (rDNA) and chloroplast $r b c \mathrm{~L}$ genes, the topology of secondary structures of internal transcribed spacer 2 (ITS2). The obtained results helped to confirm the presence of $C$. oleofaciens in the algae flora of Ukraine. Also, the authors of the article discuss the differences in the secondary structure of ITS2 in different strains of $C$. oleofaciens associated with the presence of compensatory base change (CBC), hemi-CBC in helices I and II, as well as deletions in helix IV and providing a basis for the hypothesis of the existence of cryptic species within $C$. oleofaciens. The obtained data can be used at the stage of preliminary selection of biochemical research objects.
\end{abstract}

Keywords: Chlorococcum oleofaciens; 18S rDNA; rbcL; ITS2; molecular phylogeny; morphology

\section{Introduction}

Chlorococcum Menegh. is one of the largest genera of the order of Chlamydomonadales, containing approximately about 50 species (Ettl and Gärtner, 1988, 1995, 2014). Among Chlorococcum species, Chlorococcum oleofaciens Trainor \& H.C. Bold is well studied at both the ultrastructural and molecular levels. Besides, this species is characterized by such an important feature as the ability to accumulate oils in large quantities, which with aging cells can become yellow-orange.

C. oleofaciens was first separated from the soil of a farm field near Duanesburg, New York (Trainor and Bold, 1953). Hereafter, a number of similar species were described which, after revision of the morphological features, were summarized by G. Ettl and G. Gärtner (1995) into six synonyms for C. oleofaciens: C. aquaticum P. A. Archibald, C. croceum P. A. Archibald et H. C. Bold, C. granulosum P. A. Archibald, C. microstigmatum P. A. Archibald et H. C. Bold, C. nivale P. A. Archibald, C. rugosum P. A. Archibald et H. C. Bold. Later, another revision was carried out, in which, in addition to studying the morphology, the attention was paid to phylogenetic analysis, as well as reconstruction of the secondary structure of internal transcribed spacers ITS and ITS2 (Kawasaki et al., 2015). 18 samples that corresponded to strains of $C$. oleofaciens from different culture collections, as well as to supposed synonyms and related species, were covered by the study. As a result, C. croceum, C. gelatinosum P. A. Archibald et H. C. Bold, Neospongiococcum gelatinosum (P. A. Archibald et H. C. Bold) Ettl et Gärtner, C. sphacosum P. A. Archibald et H. C. Bold, C. granulosum and C. tatrense P. A. Archibald have been confirmed to be synonyms for $C$. oleofaciens. At the same time C. microstigmatum, C. rugosum, C. aquaticum and C. nivale were recognized to be independent species, and Macrochloris rubrioleum Yur. Kawas. \& Nakada has been described as a new species to science. As the main morphological criteria for the differentiation of species, the authors used the size of the cells, the degree of thickening of the cell wall with the age of the cultures, the shape, size and position of stigma in zoospores and the color of the oils accumulated in old cells. On the basis of molecular analysis, the different positions of the newly separated species in the phylogenetic tree (although all belonged to the Stephanosphaerinia clade) and the presence of a specific set of nucleotide substitutions in the secondary structure of ITS and ITS2 were shown.

The systematic position of $C$. oleofaciens still remains not fully resolved. In the description, this species was assigned to the family Chlorococcaceae, order Chlorococcales, where it remained for a long period (Trainor, Bold, 1953; Ettl and Gärtner, 1995; Andreeva, 1998). The application of molecular genetic methods led to revision of the taxonomy of many green algae genera, including Chlorococcum. It was proposed to exclude from Chlorococcaceae a number of species of Chlorococcum, which have cytological and molecular features of protosiphonal algae (Friedl, 1997). Such species as C. oleofaciens, C. minimum Ettl et Gärtner, C. ellipsoideum Deason \& H. C. Bold, C. rugosum, C. vacuolatum R. C. Starr, C. sphacosum, C. gelatinosum and others were transferred to the family Neospongiococcaceae (Kostikov et al., 2001) on the basis of a single core presence, a paren- 
tal chloroplast with a clearly discernable perinode with a continuous starch sheath. The polyphyleticity of the genus Chlorococcum has been currently shown, as well as its species belonging to the clades of Moewusinia, Tatrensinia and Stephanosphaerinia within the order of Chlamydomonadales (Nakada et al., 2008; Kawasaki et al., 2015; Neustupa et al., 2015; Nakada and Tomita, 2011, 2016).

A long period of inconsistency in the number of synonymous taxonomic units of $C$. oleofaciens and the independence of certain species complicated the notion of geographical spread of $C$. oleofaciens and species derived from the status of its synonyms. The issue of the distribution of $C$. oleofaciens and species, the independence of which was for a certain time doubtful, is also relevant for the territory of Ukraine. C. oleofaciens has been repeatedly noted in various ecotopes of Ukraine since 1985 (Kostikov et al., 2001; Maltseva, 2009; Tsarenko et al., 2011). But with the further use of these data, it should be taken into account that by the methods of molecular phylogeny, the presence of several closely species related to C. oleofaciens has been found, the morphological differences between which were only recently shown (Kawasaki et al., 2015), as well as the possible presence of cryptic and pseudocritic taxonomic units. Bearing in mind that $C$. oleofaciens is able to accumulate a large amount of oil, its strains can have biotechnological value, including for biofuel production (Abomohra et al., 2012; Del Río et al., 2015). At the moment, the prospect of a typical strain of C. oleofaciens SAG 213-11 for providing a source of fatty acids has been confirmed (Abomohra et al., 2012; Del Río et al., 2015, 2017). However, it should also be borne in mind that one of the criteria, according to which C. aquaticum, C. microstigmatum, C. nivale and $C$. rugosum were excluded from the rank of synonyms of $C$. oleofaciens, is the color of accumulated oil (Kawasaki et al., 2015). It follows that its fatty acid composition is different and can have not only various composition, but also the value of both species and strains. Thus, the study of the morphological and molecular-genetic homogeneity of $C$. oleofaciens is important not only to clarify their taxonomic status, geographical distribution, phylogeny, etc., but also for the preliminary selection of biochemical research objects.

The aim of our work was to study, with the help of morphological and molecular genetic methods, the new strains of $C$. oleofaciens isolated from forest litter and soil on the territory of the Samara Forest (Dnipropetrovsk region, Ukraine) as one of the stages of formation of a biotechnologically valuable microalgae species bank in the Collection of Algae at Bohdan Khmelnytskyi Melitopol State Pedagogical University CAMU (WDCM 1158).

\section{Materials and methods}

The objects of the study were strains CAMU MZ-Ch4 and CAMU MZ-Ch27, isolated from forest litter and soil in the oakwood of the Samara Forest (coordinates 48³9'30.44’N 35³9'2.17’E). Samara Forest is one of the most southerly of natural forests in the steppe zone of Ukraine, and grows in the valley of the Samara river (Dnipropetrovsk region) within the zone of herb-fescue-feather grass steppes. The monoclonal strains were isolated by micropipeting of individual cells under an inverted microscope. The cultures were maintained in a liquid WC medium (Guillard and Lorenzen, 1972) under illumination with 12 hours light / 12 hours dark cycle. The time of observation of the strain was from 24 hours to 12 months.

The DNA of the investigated strains CAMU MZ-Ch4 and CAMU MZ-Ch27 were extracted using the InstaGeneTM Matrix kit according to the manufacturer's protocol. Amplification of a fragment of the 18S rDNA gene with a length of $1689 \mathrm{bp}$. was performed with a pair of primers 18S-FA2 (5'-ACC TGG TTG ATC CTG CCA GTA-3') and 18S-RB2 (5'-GAT CCT TCT GCA GGT TCA CCT ACG-3’) (Nakada et al., 2010). Amplification conditions: initial denaturation $-5 \mathrm{~min}$ at $95^{\circ} \mathrm{C}$, followed by 32 cycles (denaturation at $94^{\circ} \mathrm{C}-30 \mathrm{sec}$, annealing of primers $-40 \mathrm{sec}$ at $64^{\circ} \mathrm{C}$, elongation $1.5 \mathrm{~min}$ at $72{ }^{\circ} \mathrm{C}$ ), final elongation $-5 \mathrm{~min}$ at $72^{\circ} \mathrm{C}$. Amplification of a fragment of the chloroplast gene $r b c \mathrm{~L}$ with a length of 1002-1062 bp. was performed with a pair of primers $r b c \mathrm{~L}-\mathrm{F} 9$ (5'-CGT GAC
AAA CTA AAC AAA TAT GG-3') and rbcL-R8 (5'-AAG ATT TCA ACT AAA GCT GGC A-3’) (Nakada et al., 2010). Amplification conditions: initial denaturation $-5 \mathrm{~min}$ at $95^{\circ} \mathrm{C}$, followed by 45 cycles (denaturation at $94^{\circ} \mathrm{C}-30 \mathrm{~s}$, annealing of primers $-40 \mathrm{~s}$ at $60{ }^{\circ} \mathrm{C}$, elongation $-1.2 \mathrm{~min}$ at $72{ }^{\circ} \mathrm{C}$ ), final elongation $-5 \mathrm{~min}$ at $72{ }^{\circ} \mathrm{C}$. Amplification of the site of ITS1-5.8S-ITS2 rDNA with a length of $680 \mathrm{bp}$ was performed with a pair of primers ITS1 (5'-TCC GTA GGT GAA CCT GCG G-3') and ITS4 (5'-TCC TCC GCT TAT TGA TAT GC-3') (White et al., 1990). Amplification conditions: initial denaturation $-5 \mathrm{~min}$ at $95{ }^{\circ} \mathrm{C}$, followed by 35 cycles (denaturation at $94{ }^{\circ} \mathrm{C}-30 \mathrm{~s}$, annealing of primers $-30 \mathrm{~s}$ at $60^{\circ} \mathrm{C}$, elongation $-1 \mathrm{~min}$ at $72^{\circ} \mathrm{C}$ ), final elongation $-5 \mathrm{~min}$ at $72^{\circ} \mathrm{C}$.

The resulting PCR products were visualized by horizontal agarose gel electrophoresis (1\%) and stained with SYBR® Safe (Life Technologies, USA). Purification of PCR products was carried out with a mixture of FastAP, $10 \times$ FastAP Buffer, Exonuclease I (Thermo Fisher Scientific, USA) and water. Sequencing was performed using the Genetic Analyzer 3500 sequencer (Applied Biosystems, USA). Internal primers were also used: for the $18 \mathrm{~S}$ rDNA gene, 18S-MZ-F (5'-GGC TTC ACT GTC TGG GAC TC-3') and 18S-MZ-R (5'-ATC AAC CTG ACA AGG CAA CC-3') and the primer 5'-ATG GTT CCA CAA ACA GAA AC-3' (Nozaki et al., 1995) for $r b c L$.

Editing and assembling of the consensus sequences were carried out by comparing the direct and reverse chromatograms using the Ridom TraceEdit program (ver 1.1.0) and Mega6 (Tamura et al., 2013). In addition to these fragments, 50 DNA sequences of various representatives of green algae from GenBank were used in the subsequent analysis, including Carteria obtuse AF182818 EF113416 and Carteria radiosa D89770 D86500 taken as an outgroup. The nucleotide sequences were aligned using the Mafft v7 program using the E-INS-i model (Katoh and Toh, 2010). Reconstruction of phylogenetic relations was carried out by the maximum likelihood (ML) and Bayesian (BI) methods using the HKY+G+I model. The model of nucleotide substitutions was constructed using the program jModeltest 2.1.1 (Posada, 2006). The ML trees were built in the online RAxML program (Stamatakis et al., 2008) with 1000 bootstrap iterations. BI analysis was performed using the program MrBayes-3.2.5 (Ronquist and Huelsenbeck, 2003) with the following parameters: random initial tree, number of starts -2 , number of parallel chains -4 , number of generations $-2 \times 10^{6}$, parameter record for every hundredth generation and parameter annealing $-25 \%$. Viewing and editing of trees were carried out in the program FigTree (ver 1.4.2).

The secondary structure of the ITS2 rDNA region was modeled using the Mfold version 2.3 program (Zuker, 2003). The beginning and end of ITS2 were determined by constructing a hybrid stem with the 5.8S rDNA terminal site and the complementary LSU start site. The resulting secondary structure was visualized in the program PseudoViewer3 (Byun and Han, 2009).

\section{Results}

Phylum Chlorophyta

Class Chlorophyceae

Order Chlamydomonadales

The Oleo-clade within Stephanosphaerinia clade

Genus Chlorococcum

Species Chlorococcum oleofaciens

Type: Trainor and H. C. Bold (1953) Figs. 20-41, 60, 61 (holotype based on culture FRT-2 [= SAG 213-11]).

Synonyms: C. croceum P. A. Archibald \& H. C. Bold, C. gelatinosum P. A. Archibald \& H. C. Bold, Neospongiococcum gelatinosum (P. A. Arch, H. C. Bold) H. Ettl \& G. Gärtner, C. sphacosum P. A. Archibald \& H. C. Bold, C. granulosum P. A. Archibald, C. tatrense P. A. Archibald.

\section{Chlorococcum oleofaciens strain CAMU MZ-Ch4}

Young cells spherical, occasionally spherical or ellipsoidal (Fig. 1A). Mature vegetative cells usually spherical (Fig. 1B). Cell walls in 
7-d-old cultures smooth and thin (up to $1 \mu \mathrm{m}$ ), in 3-month-old cultures thicker than those of young cells (up to 3-4 $\mu \mathrm{m}$ ) (Fig. 1C). Single parietal hollow, cupshaped chloroplast with a small apical opening, sometimes with cracks. Single spherical pyrenoid with a continuous starch sheath located in the thickened part of the chloroplast. Pyrenoid often has irregular or gnarly shape with age of the culture (Fig. 1B). Nucleus is one, large, placed in the center of the cell or slightly displaced closer to the apical opening of the chloroplast. Young cells usually contain two contractile vacuoles
(Fig. 1A). Orange or colorless oil droplets accumulating in older cells (Fig. $1 F$ ). Asexual reproduction by 2 to 64 aplanospores or zoospores produced in spherical sporangia with diameters up to 30 $35 \mu \mathrm{m}$ (Fig. 1G). Zoospores ellipsoidal to cylindrical with two flagella longer than the cell (Fig. 1D). Parietal chloroplast with a central pyrenoid and an anterior elongated elliptical stigma (Fig. 1E). Nucleus posterior to the pyrenoid. Diameter of young vegetative cells usually $8-10 \mu \mathrm{m}$ and mature cells up to $18-26 \mu \mathrm{m}$. Zoospores $6-9 \mu \mathrm{m}$ long and $4 \mu \mathrm{m}$ wide.

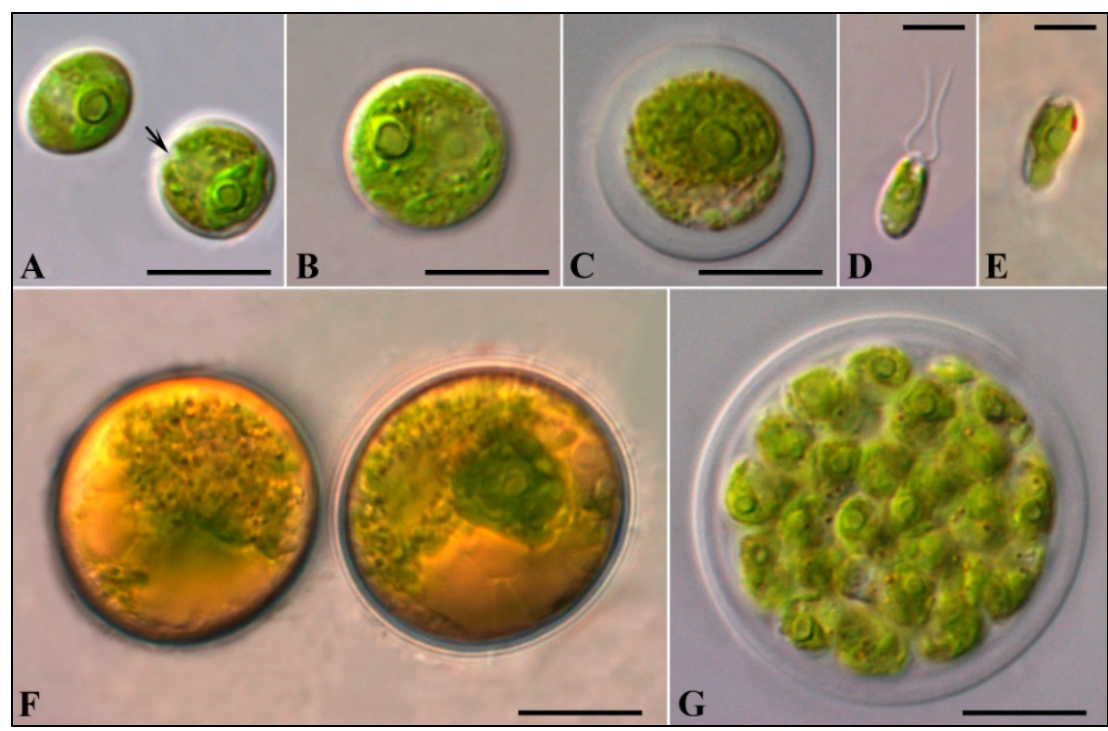

Fig. 1. Light micrographs of Chlorococcum oleofaciens strain MZ-Ch4. A. Young spherical and ellipsoidal cells: contractile vacuole (arrow) at the apical opening of the chloroplast. $B$. Mature vegetative cell: pyrenoid with continuous starch sheath. $C$. Mature cell with the thick cell wall. D. Zoospore: two flagella longer than the cell. E. Zoospore: an anterior elongated elliptical stigma. $F$. Mature cells with orange oil

(6-month-old cultures). $G$. An aplanosporangium with aplanospores; scale bars - $10 \mu \mathrm{m}(A, B, C, F, G)$ or $5 \mu \mathrm{m}(D, E)$

Habitat: the fermentation horizon of Quercus robur L. forest litter, Samara Forest (48³9'30.44”N 35³9'2.17’E), Dnipropetrovsk region, Ukraine, 2.05.2012. Forest litter temperature $-20^{\circ} \mathrm{C}$, stock of dry organic matter $-0.541 \mathrm{~kg} / \mathrm{m}^{2}, \mathrm{pH}-6.07$, ash content $37.7 \%$, forest litter moisture $-4.33 \%$.

Depositing: in the Collection of Algae at Bohdan Khmelnytskyi Melitopol State Pedagogical University as a perpetually transferred culture, strain CAMU MZ-Ch4 (Fig. 1). Also available in The Collection of Algae BOROK of IBIW RAS as an active culture BOROK MZ-Ch4.

Sequence data in GenBank: Nuclear-encoded LSU rDNA partial sequence (accession MG491216), plastid gene $r b c L$ partial sequence (accession MG460305) and ITS1-5.8S-ITS2 rDNA sequence (accession MG491218).

\section{Chlorococcum oleofaciens strain CAMU MZ-Ch27}

Young vegetative cells spherical, rarely elliptical, up to $15 \mu \mathrm{m}$ in diameter (Fig. 2A). Mature cells usually spherical, occasionally oval up to $25-30 \mu \mathrm{m}$ in diameter. Cell wall smooth (up to $0.5-$ $1.0 \mu \mathrm{m}$ ), in some older cells moderately thick (up to $3.5 \mu \mathrm{m}$ ) (Fig. 2B). A single chloroplast hollow, with a small apical opening. The chloroplast contains one distinct and spherical pyrenoid with a continuous starch sheath of uniform thickness located in the basal part of the chloroplast (Fig. 2A). Mature cells uninucleate. Brownish or colorless oil droplets accumulating in older cells (Fig. 2B, C). Asexual reproduction by 2-64 aplanospores or zoospores produced in spherical sporangia with diameters up to $35 \mu \mathrm{m}$ (Fig. 2D, E). Zoospores elliptical with two apical flagella and a simple parietal chloroplast, $7.0-8.0 \mu \mathrm{m}$ long and $4.0 \mu \mathrm{m}$ wide. Stigma elliptical and anterior.

Habitat: soil (horizon $0-5 \mathrm{~cm}$ ), oak woodland (Quercus robur), within the Samara Forest (48 $\left.39^{\prime} 30.45^{\prime} \mathrm{N} 35^{\circ} 39^{\prime 2} 2.18^{\prime \prime E}\right)$, Dnipropetrovsk region, Ukraine, 20.06.2013. Soil temperature $22{ }^{\circ} \mathrm{C}, \mathrm{pH}-5.9$, ash content $-8.37 \%$, soil moisture $-4.33 \%$.

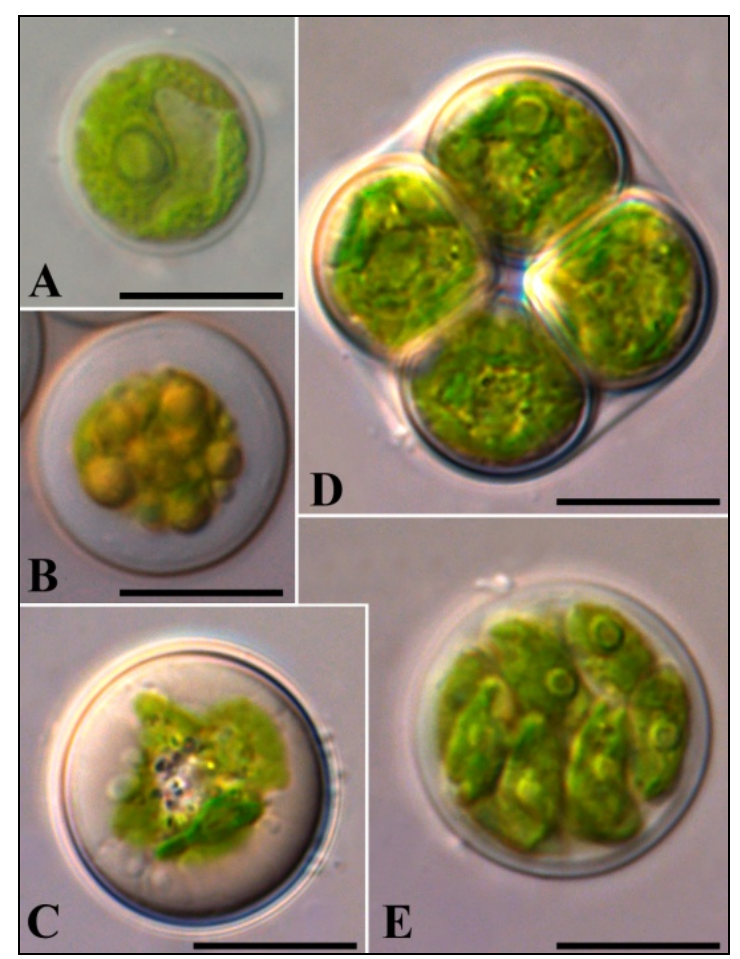

Fig. 2. Light micrographs of Chlorococcum oleofaciens strain MZ-Ch27. A. Young spherical cell with cupshaped chloroplast: pyrenoid with continuous starch sheath. $B$. Mature cell with the thick cell wall and brownish oil droplets. C. Mature cell and colorless oil. $D$. An aplanosporangium with four aplanospores. $E$. A zoosporangium with zoospores; scale bars $-10 \mu \mathrm{m}$ 
Depositing: in the Collection of Algae at Bohdan Khmelnytskyi Melitopol State Pedagogical University as a perpetually transferred culture, strain CAMU MZ-Ch27 (Fig. 2). Also available in The Collection of Algae BOROK of IBIW RAS as an active culture BOROK MZ-Ch27.

Sequence data in GenBank: Nuclear-encoded LSU rDNA partial sequence (accession MG491217), plastid gene $r b c L$ partial sequence (accession MG460306) and ITS1-5.8S-ITS2 rDNA sequence (accession MG491219).

Phylogenetic analyses based on the 18S rRNA and rbcL genes. Traditionally, taxonomic studies and the determination of phylogenetic relationships of green algae are carried out by using the nuclear gene SSU rDNA (18S) as a molecular marker (Nakada et al., 2008; Neustupa et al., 2011; Kawasaki et al., 2015; Nakada and Tomita, 2016). Nucleotide sequences of this gene are accumulated the largest number for volvocalean algae and on its basis it has been proposed to isolate 21 separate clades within the order of Chlamydomonadales (Nakada et al., 2008; Neustupa, 2015). However, the use of such a highly conserved gene as 18S rDNA does not always make it possible to solve the research objectives. The low variability of this gene sometimes makes it impossible to determine the taxonomic position of closely related species, that often reduces the use of 18S rDNA to the separation of evolutionarily older taxonomic units of green algae (Neustupa et al., 2011). Taking into account that in the last revision of $C$. oleofaciens and closely related species, only nuc- lear genes were used as molecular markers in phylogenetic reconstruction, it was expedient to build a tree based only on the 18S rDNA gene. To accomplish this, we obtained nucleotide sequences of this gene with a length of 1689 bp for the investigated strains CAMU MZ-Ch4 and CAMU MZ-Ch27. Sequences of eight different strains of $C$. oleofaciens were also included in the analysis, including the type strain SAG 213-11. In addition to different species of the genus Chlorococcum, the representatives of other closely related genera volvocalean were also included in the phylogenetic tree (Fig. 3). The reconstruction of phylogenetic connections by maximum likelihood methods (ML, where LB is the bootstrap value) and Bayes (BI, where PP is a posteriori probability) with a large statistical support (100 LB, $100 \mathrm{BI})$ showed belonging of strains CAMU MZ-Ch4, CAMU MZ-Ch27 to Oleo-clade sensu Kawasaki et al. (2015), which in turn is a part of the Stephanosphaerinia clade. In this case, the apical part of the Oleo-clade, represented by a sub-clade of different strains of $C$. leofaciens, is formed with low values of LB and BI (85 and 72, respectively), which does not allow one to speak with full confidence about its stability (Fig. 3). Thus, strains of CAMU MZ-Ch4 and CAMU MZ-Ch27 may be closely related to other species besides $C$. oleofaciens, inside the Oleo-clade. The remaining sample selection under the analysis was split into clades corresponding to the modern understanding of the phylogeny of Chlamydomonadales (Nakada et al., 2008; Kawasaki et al., 2015; Neustupa et al., 2015).

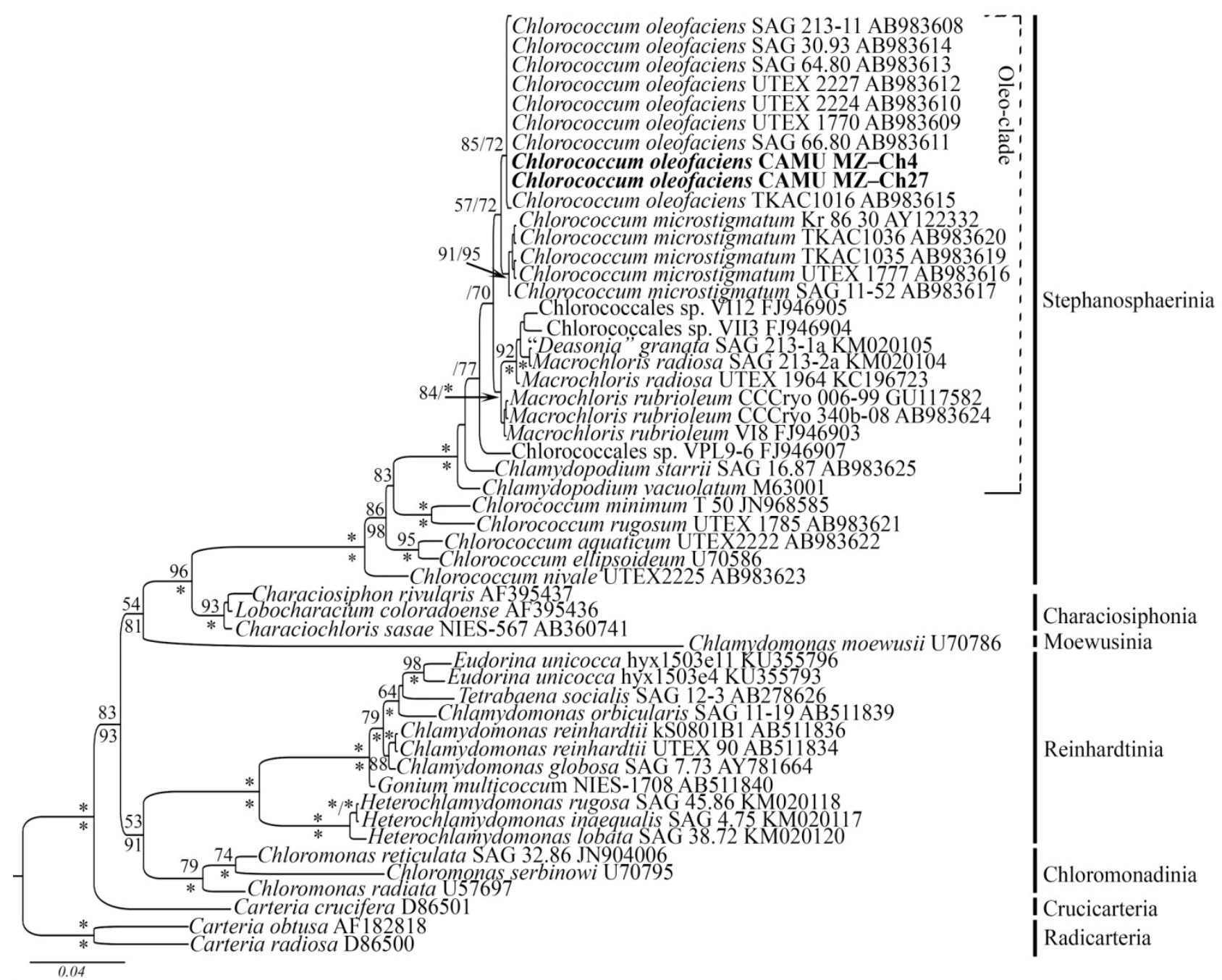

Fig. 3. Phylogenetic analysis for Chlorococcum oleofaciens CAMU MZ-Ch4, CAMU MZ-Ch27 (indicated in bold) constructed from an alignment with 50 sequences and 1703 characters (partial SSU rDNA). Values above horizontal lines (in front of the slash) are bootstrap support as RAxML analyses ( $<50$ are not shown), values below horizontal lines (behind the slash) are Bayesian posterior probabilities

( $<70$ are not shown); * - values at the level 100 for LB and BI. Species from Radicarteria clade were chosen as outgroup. Model of nucleotide substitution $-\mathrm{HKY}+\mathrm{G}+\mathrm{I}$ 
Often, the low resolving power of the 18S rDNA gene when separating closely related species can be solved by bringing in other molecular markers. One of them can be presented by the chloroplast gene $r b c \mathrm{~L}$, which encodes a large subunit of the ribulosebisphosphate-carboxylase ferment. In the study of green algae phylogeny, the variable gene $r b c \mathrm{~L}$ is widely used in conjunction with the conservative 18S rDNA one (Neustupa et al., 2013; Fučíková et al., 2014; Skaloud et al., 2016).

Therefore, for a more complete and reliable analysis of the phylogenetic position of CAMU MZ-Ch4 and CAMU MZ-Ch27 strains, we have sequenced the fragments of the $r b c \mathrm{~L}$ gene with the length of 1002 bp (for CAMU MZ-Ch27) and of 1062 bp (for CAMU MZCh4). Phylogenetic analyses (BI, ML) for two genes also confirmed belonging of these strains to the Oleo-clade (Fig. 4). This analysis with the maximum statistical support (100 LB, $100 \mathrm{BI}$ ) showed a close relationship of CAMU MZ-Ch4, CAMU MZ-Ch27 and different strains of $C$. oleofaciens. The addition of the second gene to the analysis did not break the clade system within Chlamydomonadales isolated with 18S rDNA (Nakada et al., 2008; Kawasaki et al., 2015; Neustupa et al., 2015). One of the problems in constructing phylogenetic trees based on two genes for volvocalean is the smaller number of $r b c \mathrm{~L}$ gene sequences obtained today, compared to $18 \mathrm{~S}$ rDNA. This resulted in a decrease in the total sample selection to 28 various species from the order of Chlamydomonadales and the loss of such close to C. oleofaciens species as C. microstigmatum, Macrochloris rubrioleum and others from analysis.

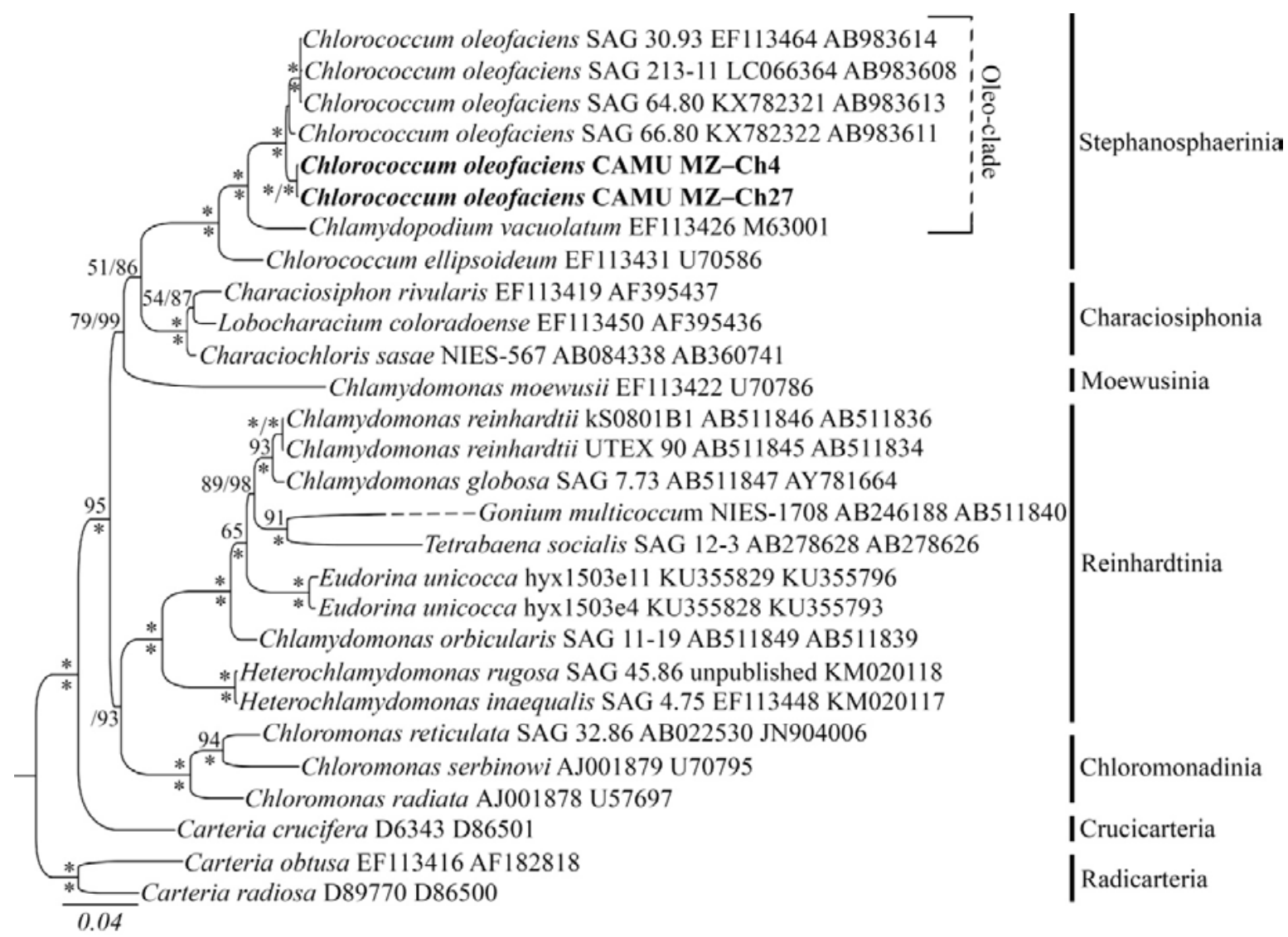

Fig. 4. Phylogenetic analysis for Chlorococcum oleofaciens CAMU MZ-Ch4, CAMU MZ-Ch27 (indicated in bold) constructed from an alignment with 26 sequences and 2809 characters (partial SSU rDNA gene and partial $r b c L$ gene). Values above horizontal lines (in front of the slash) are bootstrap support as RAxML analyses ( $<50$ are not shown), values below horizontal lines (behind the slash) are Bayesian posterior probabilities ( $<70$ are not shown); * - values at the level 100 for LB and BI. Species from Radicarteria clade were chosen as outgroup. Model of nucleotide substitution $-\mathrm{HKY}+\mathrm{G}+\mathrm{I}$

Phylogenetic analyses based on the ITS region. The second internal transcribed spacer ITS2, as a rapidly evolving part of the nuclear operon, is successfully applied to solve the issues of phylogenetic status of systematically critical taxonomic units at the species and even genus levels (Coleman, 2003, 2009). The construction of secondary structure models of ITS2 allows determination of the homologous sites in individual ITS2 helices and the presence of compensatory base change (CBC) and hemi-CBC (hCBC) involving change of the nucleotide. It has been found that the presence of at least one $\mathrm{CBC}$ in the secondary structure of ITS2 in I-III helices of two organisms correlates with their complete sexual incompatibility. At the same time, it was shown that the presence of hCBC is not related to the possibility of crossing, but may indicate the inter-species differences (Coleman, 2009). In connection with this, the analysis of secondary structure of ITS2 topology can be used not as a universal method for distinguishing species, but as one of the approaches in combination with other molecular genetic or morphological methods. To confirm the taxonomic status of strains CAMU MZ-Ch27 and CAMU MZ-
Ch27, we modelled secondary structures of the ITS2 rRNA region. Analysis of the obtained models topology showed their complete identity, which confirmed the strains as belonging to one biological species. These models had such key distinguishing features of the secondary structure of ITS2 in green algae (Coleman 2007): the pyrimidine-pyrimidine unpaired site of T-T in helix II, the conserved region of YRGGTAGGC on the 5' side of helix III, which in this case assumed the form of TGGGTGGGC taking into account the $A \rightarrow G$ transaction (Fig. 5). It should also be noted that there were present the conservative sites in the core model and the basal parts of helices (I-III) for the classes Chlorophyceae and Ulvophyceae in the secondary structure of ITS2 of the studied strains proposed by Caisová et al. (2013). Thus, helix I begins with pairs of T-G and C-G, the unique spacer between helices I and II consists of their three nucleotides ANC, helix II begins with pairs of T-G and G-T, the unique spacer between helices II and III consists of nine nucleotides and contains conserved region AANNNNAGA, helix III begins in pairs G-C, G-C (Fig. 5). 


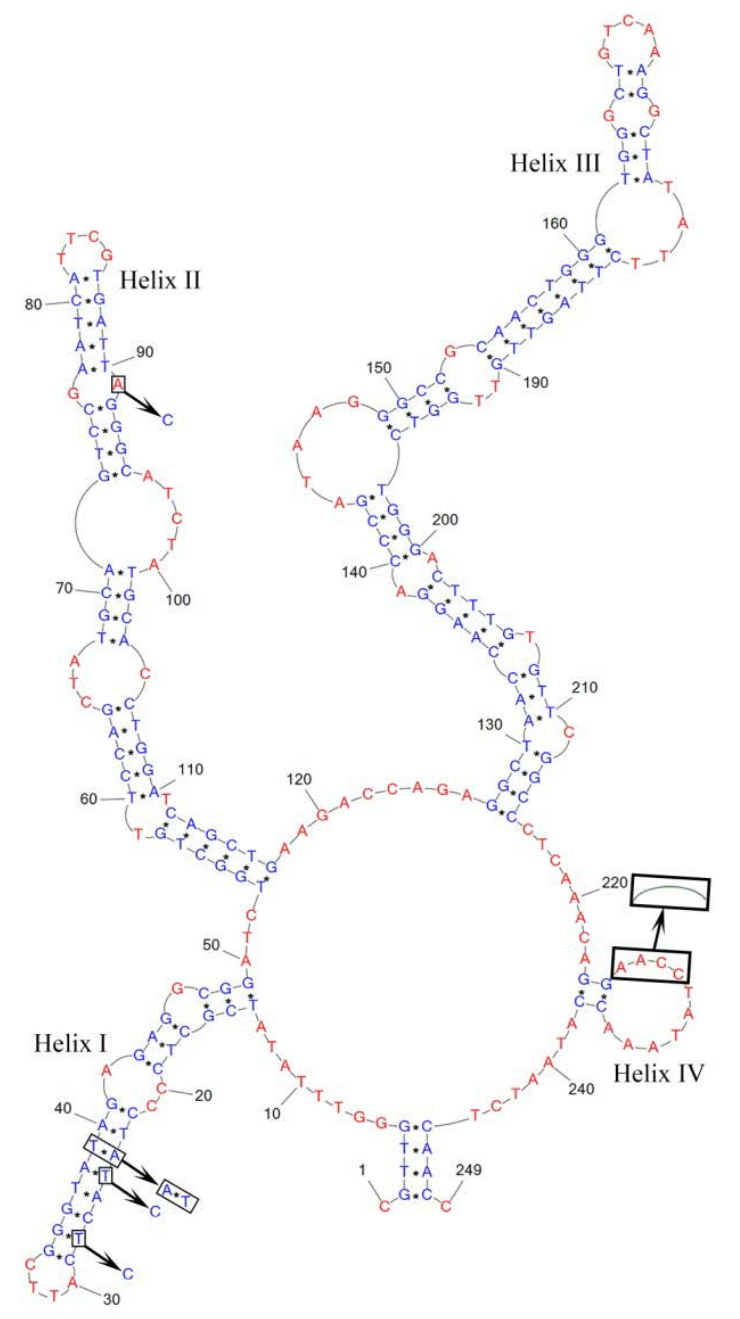

Fig. 5. Predicted secondary structure of the ITS2 sequence of Chlorococcum oleofaciens strain CAMU MZ-Ch4. Base numbering is indicated every 10 bases, the four helices are numbered with Roman numbers. Differences characteristic for the strain Chlorococcum oleofaciens strain SAG 213-11 (accession number AB983626) are shown by nucleotides outside the secondary structure

The comparison of the secondary structure topology of ITS2 rRNA strains CAMU MZ-Ch27 and CAMU MZ-Ch27 was also performed with similar models obtained by Kawasaki et al. (2015) for eight different strains of $C$. oleofaciens (including the type strain SAG 213-11). The analysis showed that only the strain TKAC 1016 is characterized by complete identity to the models we obtained. In this case, the remaining strains of $C$. oleofaciens by the number of differences can be divided into two groups, each of which differs by an equal number of nucleotide substitutions (but not their position in the helices). So the first group includes strains SAG 66.80 and UTEX 2227, which differ from our strains and strain TKAC 1016 with five hCBC: three in helix I and two in helix II. The second group includes strains SAG 213-11, UTEX 2224, SAG 30.93, SAG 64.80 and UTEX 1770, which are characterized by more significant substitutions: one CBC in helix I, two hCBC in helix I and one hCBC in helix II (Fig. 5). In addition to the listed differences, the type strain SAG 213-11 is characterized by four deletions in the unpaired sites of helix IV (Fig. 5) compared to these strains and all strains of $C$. oleofaciens, studied by Kawasaki et al. (2015).

\section{Discussion}

Species of the genus Chlorococcum are typical representatives of algal flora in the soil (Kostikov et al., 2001; Maltseva, 2009; Tsarenko et al., 2011; Scherbina et al., 2014; Shekhovtseva et al., 2015). On the territory of Ukraine, C. oleofaciens has been observed repeatedly in soils of different natural zones and types of biogeocoenoses: in soils of beech forests of the Ukrainian Carpathians, oak forests and mountain meadows of the Crimean mountains. In the forest zone the species has been noted in oak, alder, aspen forests of Volyn region; pine forests and robinia plantations in Sumy region; bottomland and grass meadows in Volyn and Zhytomyr regions, as well as on the fallow soil in Volyn region. In the forest-steppe, it has been found in pine forest in Sumy region and in hornbeam and pine forests in Cherkassy region (Kostikov et al., 2001). In the steppe zone, the species has been noted twice as C. (Neospongiococcum) oleofaciens in the soil algae communities of pine forest and birch outliers of the Samara Forest in Dnipropetrovsk region (Maltseva, 2009). The former synonym and the closest one, in terms of molecular phylogeny on the basis of the 18S rDNA gene, to C. oleofaciens species C. microstigmatum has also been noted in the soils of Ukraine more than once. In Polissia it has been found in mixed birch-aspen forests of Volyn region and pine forests of Kyiv region; in the forest-steppe in the hornbeam-oak and hornbeam forests of Cherkassy region and oak forests of Kyiv region (Kostikov et al., 2001). In the steppe zone C. microstigmatum has been noted as a dominant in the upper horizon of the soil of the linden-ash ravine grove (Bolshoi Kapitanovskii ravine forest, Dnipropetrovsk region) (Cherevko, 1993) and in the soil of the virgin steppe (Dnipropetrovsk region) (Cherevko and Maltseva, 1995). However, with the further use of these data, it should be borne in mind that for 20 years the understanding of $C$. oleofaciens sensu lato included adding to the list of synonyms both $C$. microstigmatum, and C. aquaticum, and $C$. nivale and C. rugosum, which after the revision were given the status of independent species (Kawasaki et al., 2015).

Strains of C. oleofaciens CAMU MZ-Ch4 and MZ-Ch27 were isolated from the samples of forest litter and soil selected in the bottomland oak forest of the Samara Forest (Dnipropetrovsk region) in 2012-2013, where we laid test plots for seasonal studies of soil algae. In this case, strain MZ-Ch4 represents spring litter samples of 2012, whereas MZ-Ch27 represents summer soil samples of 2013. The presence of the same species in various biogeocoenotic horizons of forest biogeocoenosis indicates a similarity of the composition of algae of forest litter and the soil under it in steppe oak forests (Jaccard's coefficient varies in the range of 22.1-23.5\%) (Maltsev, 2015). On the other hand, the change of the species habitat in different seasons gives evidence of a change in the conditions of algae existence (temperature and water regime, biological activity, etc.) (Scherbina et al., 2014; Maltsev et al., 2017a).

A comparison of morphological features of the studied strains shows that the main differences are in the larger diameter of adult cells and the smaller length of zoospores in the strain of C. oleofaciens CAMU MZ-Ch27 compared to CAMU MZ-Ch4. Despite this, the morphology of both strains fully coincides with the refined diagnosis of the species C. oleofaciens (Kawasaki et al., 2015).

Molecular-phylogenetic analysis based on two genes showed with high statistical support the strains CAMU MZ-Ch4 and MZ-Ch27 belonging to the subclade $C$. oleofaciens (Fig. 3, 4). However, the analysis of the secondary structure of ITS2 indicates some peculiarities. Firstly, the attention is drawn to the complete coincidence of the model topology of strains isolated from very remote locations with a significant time difference - Ukrainian CAMU MZ-Ch4 (05.2012), MZCh27 (06.2013) and Japanese TKAC 1016 (06.2005), which was isolated from the soil in Oamishirasato, Chiba Prefecture, Japan (35³20 N, $140^{\circ} 180 \mathrm{E}$ ). Secondly, one should take into account the presence of three hCBC and one CBC in these strains, which distinguish them from other strains of C. oleofaciens, including the type SAG 213-11 (Fig. 5). Considering that the presence of CBC only in helices II and III is connected with the sexual incompatibility (Coleman, 2009), it is possible that the authors of the last revision (Kawasaki et al., 2015) did not raise the issue of another status of the strain C. oleofaciens TKAC 1016. However, our isolation of two new strains with the same molecular differences from the rest of the sample of strains of $C$. oleofaciens may indicate the existence of cryptic species within a given taxon. 
Even when describing the species, the authors drew attention to such feature as the ability to accumulate a significant amount of oil in cells during the cultures aging (Trainor, Bold, 1953). Later this peculiarity attracted the biochemists' attention and it was found that C. oleofaciens is characterized by accumulation of a large amount of fatty acids: unsaturated - oleic and linoleic ones, saturated - palmitic one (Cojocaru et al., 1988). Hereafter, with the development of ideas for the production of biomass fuel, it was found that saturated fatty acids increase the octane number and biofuel resistance to degradation, unsaturated fatty acids reduce the pour point and gelation of fuel at low temperatures, and algae are generally a promising raw material for biodiesel production (Talebi et al., 2013; Maltsev et al., 2017b). These discoveries led to a further study of the biochemistry of C. oleofaciens. The following parameters of $C$. oleofaciens as a promising source of fatty acids were found: the ability to store biomass up to 2.6 CDW (g L ${ }^{-1}$ ) and a high degree of fat storage capacity - up to $35 \mathrm{mg} \mathrm{l}^{-1} \mathrm{~d}^{-1}$ (Abomohra et al., 2012); ability to increase the productivity of fatty acid accumulation by $138 \%$ under nitrogen starvation, accumulate up to $13.6 \%$ of palmitic and $25.0 \%$ of linoleic fatty acids (\% of total FA) (Del Rio et al., 2014). However, despite the abundance of biochemical characteristics, it is currently impossible to say whether they concern the species as a whole, since the data were mainly obtained for the type strain SAG 213-11. Meanwhile, in deriving from the rank of synonyms $C$. aquaticum, $C$. microstigmatum, $C$. nivale and C. rugosum, the authors used the color of accumulated oil as one of the criteria (Kawasaki et al., 2015). Therefore, the importance of studying fatty acid composition in different strains of $C$. oleofaciens may be determined by a successful experience in the separation of closely related species from the genus Parietochloris Watanabe et Floyd on the basis of lipidomic analysis (Řezanka et al., 2017). Perhaps, it is the application of biochemistry methods in combination with morphological and molecular genetic methods that will allow us to solve the question of the belonging to cryptic species with a wide distribution area of strains $C$. oleofaciens CAMU MZ-Ch4, CAMU MZ-Ch27 and TKAC 1016 in further studies.

\section{Conclusions}

In this study, based on the phylogeny of the 18S rDNA and rbcL genes, a comparison of the secondary structures of ITS2 and light microscopy, two new strains of C. oleofaciens (CAMU MZ-Ch4 and CAMU MZ-Ch27) are described as possible sources of fatty acids. They were isolated from forest litter and soil in oak woodland within the Samara Forest (Dnipropetrovsk region, Ukraine). Based on the topology analysis of the secondary structure of ITS2, the presence of three groups of strains within C. oleofaciens is shown, they differ in CBC and hCBC in helices II and III. The identity of two new Ukrainian strains and the Japanese strain C. oleofaciens TKAC 1016 is established. It is suggested that there may be a number of cryptic species within C. oleofaciens.

\section{References}

Abomohra, A. E.-F., Wagner, M., El-Sheekh, M., \& Hanelt, D. (2012). Lipid and total fatty acid productivity in photoautotrophic fresh water microalgae: Screening studies towards biodiesel production. Journal of Applied Phycology, 25(4), 931-936.

Andreeva, V. M. (1998). Pochvennyie i aerofilnyie zelenyie vodorosli (Chlorophyta: Tetrasporales, Chlorococcales, Chlorosarcinales) [Soil and aerophilic green algae (Chlorophyta: Tetrasporales, Chlorococcales, Chlorosarcinales)]. Nauka, St. Petersburg (in Russian).

Byun, Y., \& Han, K. (2009). PseudoViewer3: Generating planar drawings of largescale RNA structures with pseudoknots. Bioinformatics, 25, 1435-1437.

Caisová, L., Marin, B., \& Melkonian, M. (2013). A consensus secondary structure of ITS2 in the Chlorophyta identified by phylogenetic reconstruction. Protist, 164, 482-496.

Cherevko, S. P. (1993). Pochvennyie vodorosli lesnyih biogeotsenozov podzonyi nastoyaschih stepey Ukrainyi [Soil algae of forest phytocoenoses from true steppe subzone of Ukraine]. Algology, 3(2), 49-52 (in Russian).

Cherevko, S. P., \& Maltseva, I. A. (1995). Vodorosli pochv lesnyh biogeotsenozov Prisamarya Dneprovskogo i drevesnyih nasazhdeniy Zapadnogo Donbassa
[Soil algae of forest biogeocenoses from Dnieper Prisamarye and woody plantings of Western Donbass]. Monitoring of biogeocenotic in the steppe zone. Interuniversity collection of scientific works, 64-67 (in Russian).

Cojocarut, M., Shlosberg, M., Dubinsky, Z., \& Finkel, A. (1988). Gas chromatographic/mass spectrometric analysis of fatty acids found in aquatic algae. Biomedical and Environmental Mass Spectrometry, 16, 477-480.

Coleman, A. W. (2003). ITS2 is a double-edged tool for eukaryote evolutionary comparisons. Trends in Genetics, 19(7), 370-375.

Coleman, A. W. (2009). Is there a molecular key to the level of "biological species” in eukaryotes? A DNA guide. Molecular Phylogenetics and Evolution, 50, 197-203.

Del Río, E., Armendáriz, A., García-Gómez, E., García-González, M., \& Guerrero, M. G. (2015). Continuous culture methodology for the screening of microalgae for oil. Journal of Biotechnology, 195, 103-107.

Del Río, E., García-Gómez, E., Moreno, J., Guerrero, M. G., \& García-González, M. (2017). Microalgae for oil. Assessment of fatty acid productivity in continuous culture by two high-yield strains, Chlorococcum oleofaciens and Pseudokirchneriella subcapitata. Algal Research, 23, 37-42.

Ettl, H., \& Gärtner, G. (1988). Chlorophyta II. Tetrasporales, Chlorococcales, Gloeodendrales. In: Ettl, H., Gerloff, J., Heynig, H. \& Mollenhauer, D. (Eds.). Süßwasserflora von Mitteleuropa, 10. Gustav Fischer, Jena.

Ettl, H., \& Gärtner, G. (1995). Syllabus der Boden-, Luft- und Flechtenalgen. Gustav Fischer, Stuttgart.

Ettl, H., \& Gärtner, G. (2014). Syllabus der Boden-, Luft- und Flechtenalgen, 2nd edn. Springer Spektrum, Berlin.

Friedl, T. (1997). The evolution of the Green Algae. Plant Systematics and Evolution, 11, 87-101.

Fucíková, K., Lewis, P. O., \& Lewis, L. A. (2014). Widespread desert affiliation of trebouxiophycean algae (Trebouxiophyceae, Chlorophyta) including discovery of three new desert genera. Phycological Research, 62, 294-305.

Guillard, R. R. L., \& Lorenzen, C. J. (1972). Yellow-green algae with chlorophyllide c. Journal of Phycology, 8, 10-14.

Katoh, K., \& Toh, H. (2010). Parallelization of the MAFFT multiple sequence alignment program. Bioinformatics, 26, 1899-1900.

Kawasaki, Y., Nakada, T., \& Tomita, M. (2015). Taxonomic revision of oil-producing green algae, Chlorococcum oleofaciens (Volvocales, Chlorophyceae), and its relatives. Journal of Phycology, 51, 1000-1016.

Kostikov, I., Romanenko, P., Demchenko, E., Dariyenko, T., Mikhailyuk, T., Rybczynski, A., \& Solonenko, A. (2001). Vodorosti gruntiv Ukrainy (Istoriia i metody doslidzhennia, systema, konspekt flory) [Soil algae of Ukraine (history and methods of research, system, synopsis of flora)]. Phytosociocentr, Kyiv (in Ukrainian).

Maltsev, Y. (2015). Alhouhrupovannia riznykh bioheotsenotychnykh horyzontiv Staro-Berdianskoho lisu [Algae communities of different biogeocenotic horizons in Staro-berdyansk forest]. The Bulletin of Kharkiv National Agrarian University. Series Biology, 2(35), 87-92 (in Ukrainian).

Maltsev, Y. I., Konovalenko, T. V., Barantsova, I. A., Maltseva, I. A., \& Maltseva, K. I. (2017b). Prospects of using algae in biofuel production. Regulatory Mechanisms in Biosystems, 8(3), 455-460.

Maltsev, Y. I., Pakhomov, A. Y., \& Maltseva, I. A. (2017a). Specific features of algal communities in forest litter of forest biogeocenoses of the Steppe zone. Contemporary Problems of Ecology, 10(1), 71-76.

Maltseva, I. A. (2009). Gruntovi vodorosti lisiv stepnoi zony Ukrainy [Soil algae of the forests of steppe area of Ukraine]. Lux, Melitopol (in Ukrainian).

Nakada, T., \& Tomita, M. (2011). Chlamydomonas neoplanoconvexa nom. nov. and its unique phylogenetic position within Volvocales (Chlorophyceae). Phycological Research, 59, 194-199.

Nakada, T., \& Tomita, M. (2016). Taxonomic revision of Chlamydomonas subg. Amphichloris (Volvocales, Chlorophyceae), with resurrection of the genus Dangeardinia and descriptions of Ixipapillifera gen. nov. and Rhysamphichloris gen. nov. Journal of Phycology, 52, 283-304.

Nakada, T., Misawa, K., \& Nozaki, H. (2008). Molecular systematics of Volvocales (Chlorophyceae, Chlorophyta) based on exhaustive 18S rRNA phylogenetic analyses. Molecular Phylogenetics and Evolution, 48, 281-291.

Nakada, T., Shinkawa, H., Ito, T., \& Tomita, M. (2010). Recharacterization of Chlamydomonas reinhardtii and its relatives with new isolates from Japan. Journal of Plant Research, 123, 67-78.

Neustupa, J. I. (2015). Chlorophyta, Streptophyta p.p. (except Ulvophyceae, Charophyceae; incl. Trentepohliales). In: Wolfgang, F. (Ed.). Syllabus of plant families. A. Engler's Syllabus der Pflanzenfamilien. Part 2/1: Photoautotrophic Eukaryotic Algae Glaucocystophyta, Cryptophyta, Dinophyta/Dinozoa, Haptophyta, Heterokontophyta/Ochrophyta, Chlorarachniophyta/Cercozoa, Euglenophyta/Euglenozoa, Chlorophyta, Streptophyta p.p. Borntraeger Science Pub., GmbH.

Neustupa, J. I., Elias, M., Skaloud, P., Nemcova, Y., \& Sejnohova, L. (2011). Xylochloris irregularis gen. et sp. nov. (Trebouxiophyceae, Chlorophyta), a novel subaerial coccoid green alga. Phycologia, 50, 57-66. 
Nozaki, H., Itoh, M., Sano, R., Uchida, H., Watanabe, M. M., \& Kuroiwa, T. (1995) Phylogenetic relationships within the colonial Volvocales (Chlorophyta) inferred from $r b c L$ gene sequence data. Journal of Phycology, 31, 970-979.

Posada, D. (2006). Modeltest server: A web-based tool for the statistical selection of models of nucleotide substitution online. Nucleic Acids Research, 34, 700-703.

Řezanka, T., Nedbalova, L., Lukavský, J., Procházková, L., \& Sigler, K. (2017). Lipidomic analysis of two closely related strains of the microalga Parietochloris (Trebouxiophyceae, Chlorophyta). Algal Research, 25, 473-482.

Ronquist, F., \& Huelsenbeck, J. P. (2003). MrBayes 3: Bayesian phylogenetic inference under mixed models. Bioinformatics, 19, 1572-1574.

Scherbina, V. V., Maltseva, I. A., \& Solonenko, A. N. (2014). Peculiarities of postpyrogene development of algae in steppe biocenoses at Askania Nova Biospheric National Park. Contemporary Problems of Ecology, 7(2), 187-191.

Shekhovtseva, O. G., \& Maltseva, I. A. (2015). Physical, chemical, and biological properties of soils in the city of Mariupol, Ukraine. Eurasian Soil Science, 48(12), 1393-1400.

Skaloud, P., Friedl, T., Hallmann, C., Beck, A., \& Dal Grande, F. (2016). Taxonomic revision and species delimitation of coccoid green algae currently assigned to the genus Dictyochloropsis (Trebouxiophyceae, Chlorophyta). Journal of Phycology, 52, 599-617.
Stamatakis, A., Hoover, P., \& Rougemont, J. (2008). A rapid bootstrap algorithm for the RAxML web-servers. Systematic Biology, 75, 758-771.

Talebi, A. F., Mohtashami, S. K., Tabatabaei, M., Tohidfar, M., Bagheri, A., Zeinalabedini, M., Mirzaei, H. H., Mirzajanzadeh, M., Shafaroudi, S. M., \& Bakhtiari, S. (2013). Fatty acids profiling: A selective criterion for screening microalgae strains for biodiesel production. Algal Research, 2, 258-267.

Tamura, K., Stecher, G., Peterson, D., Filipski, A., \& Kumar, S. (2013). MEGA6: Molecular evolutionary genetics analysis version 6.0. Molecular Biology and Evolution, 30, 2725-2729.

Trainor, F. R., \& Bold, H. C. (1953). Three new unicellular Chlorophyceae from soil. American Journal of Botany, 40, 758-767.

Tsarenko, P. M., Wasser, S., \& Nevo, E. (2011). Algae of Ukraine: Diversity, nomenclature, taxonomy, ecology and geography. Vol. 3. Chlorophyta. A. R. G. Rugell: Gantner Verlag K. G., Königstein.

White, T. J., Bruns, T., Lee, S., \& Taylor, J. W. (1990). Amplification and direct sequencing of fungal ribosomal RNA genes for phylogenetics. In: Innis, M. A., Gelfand, D. H., Sninsky, J. J., \& White, T. J. (Eds.). PCR protocols: A guide to methods and applications. Academic Press Inc., New York.

Zuker, M. (2003). Mfold web server for nucleic acid folding and hybridization prediction. Nucleic Acids Research, 31, 3406-3415. 